\title{
An Unusual Presentation of Tumor Lysis Syndrome in a Patient with Advanced Gastric Adenocarcinoma: Case Report and Literature Review
}

\author{
Danica Maria Vodopivec, Jose Enrique Rubio, Alessia Fornoni, and Oliver Lenz
}

Department of Nephrology and Hypertension, Jackson Memorial Hospital, 1611 North West 12th Avenue, Miami, FL 33101, USA

Correspondence should be addressed to Danica Maria Vodopivec, danica.vodopivec19@gmail.com

Received 28 November 2011; Revised 22 February 2012; Accepted 13 March 2012

Academic Editor: Glenn Bubley

Copyright (C 2012 Danica Maria Vodopivec et al. This is an open access article distributed under the Creative Commons Attribution License, which permits unrestricted use, distribution, and reproduction in any medium, provided the original work is properly cited.

\begin{abstract}
Tumor lysis syndrome (TLS) is characterized by hyperuricemia, hyperkalemia, hyperphosphatemia, and secondary hypocalcemia in patients with a malignancy. When these laboratory abnormalities develop rapidly, clinical complications such as cardiac arrhythmias, acute renal failure, seizures, or death may occur. TLS is caused by rapid release of intracellular contents by dying tumor cells, a condition that is expected to be common in hematologic malignancies. However, TLS rarely occurs with solid tumors, and here we present the second chemotherapy-induced TLS in a patient with advanced gastric adenocarcinoma to be reported in the literature. We also provide information regarding the total cases of TLS in solid tumors reported from 1977 to present day. Our methodology involved identifying key articles from existing reviews of the literature and then using search terms from these citations in MEDLINE to find additional publications. We relied on a literature review published in 2003 by Baeksgaard et al., where they gathered all total 45 cases reported from 1977 to 2003 . Then, we looked for new reported cases from 2004 to present day. All reports (case reports, brief reports, letters to editor, correspondence, reviews, journals, and short communications) identified through these searches were reviewed and included.
\end{abstract}

\section{Introduction}

Tumor lysis syndrome is a life-threatening oncologic emergency that occurs when a large amount of malignant tumor cells breakdown rapidly and release their intracellular contents into the systemic circulation causing electrolyte and metabolic disturbances, such as hyperuricemia, hyperkalemia, hyperphosphatemia, and hypocalcemia. Renal insufficiency, cardiac arrhythmias, seizures, and death due to multiorgan failure may be the final consequences of these biochemical derangements [1-8].

Tumor lysis syndrome develops usually after the initiation of chemotherapy but in rare cases may arise spontaneously before any antitumor therapy has been initiated [1, 4-19] (Table 1) (Figure 1). TLS is common in patients with hematologic malignancies with high growth rates or a large disease burden, but it is rarely observed in patients with solid tumors of which to date there are only 100 cases described in the literature [1-93] (Table 1) (Figure 2).

To the best of our knowledge, the present study case is the second report describing TLS following chemotherapy for advanced gastric adenocarcinoma [37]. Also, a review of the literature regarding TLS in solid tumors is presented and recommendations for management are discussed.

\section{Case Report}

The patient is a 57-year-old Hispanic man with a history of stage III moderately differentiated gastric adenocarcinoma intestinal type, diagnosed in late 2006. He was enrolled in a clinical trial for a new regimen of neoadjuvant chemotherapy consisting of oxaliplatin $\left(85 \mathrm{mg} / \mathrm{m}^{2}\right.$ i.v. over 2 hours on days 1 and 15$)$, docetaxel $\left(25 \mathrm{mg} / \mathrm{m}^{2}\right.$ i.v. over 30 minutes on days 
TABLE 1: Reported cases of tumor lysis syndrome in solid tumors (1977-2011).

\begin{tabular}{|c|c|c|c|c|}
\hline Tumor type & Treatment & Outcome of TLS & $\begin{array}{c}\text { Year } \\
\text { published }\end{array}$ & Reference \\
\hline \multirow{13}{*}{ Small cell carcinoma } & DOXO, CDDP, VP-16, VCR & Died & 1983 & {$[20]^{*}$} \\
\hline & DOXO, CTX, VCR & Resolved & 1983 & {$[21]^{*}$} \\
\hline & CCNU, CTX, MTX & Died & 1988 & {$[22]^{*}$} \\
\hline & CDDP, VP-16 & Resolved & 1988 & {$[22]^{\dagger}$} \\
\hline & DOXO, CTX, VCR & Resolved & 1990 & {$[23]^{*}$} \\
\hline & DOXO, IF & Resolved & 1991 & {$[24]^{\ddagger}$} \\
\hline & CDDP, VP-16 & Resolved & 1997 & {$[25]^{*}$} \\
\hline & CDDP, VP-16 & Resolved & 1997 & {$[26]^{*}$} \\
\hline & CDDP, VP-16 & Died & 1999 & {$[27]^{*}$} \\
\hline & CDDP, VP-16 & Died & 2001 & {$[28]^{*}$} \\
\hline & TOPO & Died & 2002 & {$[29]^{*}$} \\
\hline & CBCDA, VP-16 & Resolved & 2005 & {$[30]^{*}$} \\
\hline & None & Died & 2011 & {$[9]^{*}$} \\
\hline \multirow{2}{*}{ Squamous cell carcinoma } & None & Resolved & 2009 & {$[10]^{\#}$} \\
\hline & None & Died & 2009 & {$[11]^{\# \#}$} \\
\hline \multirow[t]{4}{*}{ Adenocarcinoma of the lung } & CPT-11, CDDP & Resolved & 1998 & {$[31]$} \\
\hline & None & Died & 2000 & {$[12]$} \\
\hline & $\mathrm{ZOL}$ & Died & 2005 & {$[32]$} \\
\hline & DTX & Died & 2006 & {$[33]$} \\
\hline $\begin{array}{l}\text { Mixed small cell and nonsmall cell } \\
\text { tumor of the lung }\end{array}$ & CBCDA, PTX & Died & 2002 & {$[34]$} \\
\hline \multirow{3}{*}{ GI tract } & None & Died & 1997 & {$[13]$} \\
\hline & SUN & Resolved & 2007 & {$[35]$} \\
\hline & IMA & Died & 2007 & {$[36]$} \\
\hline \multirow{3}{*}{ Gastric cancer } & None & Resolved & 2001 & {$[14]$} \\
\hline & CAP, CDDP & Resolved & 2008 & {$[37]$} \\
\hline & OX, LV, FUDR, DTX & Resolved & 2011 & Current case \\
\hline \multirow{6}{*}{ Colorectal cancer } & CPT-11 & Died & 1996 & {$[38]$} \\
\hline & CPT-11 & Died & 2000 & {$[39]$} \\
\hline & None & Resolved & 2003 & {$[15]$} \\
\hline & 5-FU, LV, CPT-11 & Died & 2004 & {$[40]$} \\
\hline & $\mathrm{CE}$ & Died & 2008 & {$[41]$} \\
\hline & CPT-11, 5-FU, F, BEV & Died & 2008 & {$[42]$} \\
\hline \multirow{2}{*}{ Hepatoblastoma } & S & Died & 1990 & {$[43]$} \\
\hline & CDDP, VCR, 5-FU & Resolved & 2010 & {$[44]$} \\
\hline \multirow{12}{*}{ Hepatocellular carcinoma } & TACE & Died & 1998 & {$[45]$} \\
\hline & TACE & Resolved & 1998 & {$[45]$} \\
\hline & None & Died & 2003 & {$[15]$} \\
\hline & $\mathrm{RF}$ & Resolved & 2005 & {$[46]$} \\
\hline & $\mathrm{TH}$ & Died & 2006 & {$[47]$} \\
\hline & TOCE & Died & 2007 & {$[48]$} \\
\hline & TACE & Resolved & 2008 & [49] \\
\hline & TACE & Resolved & 2009 & {$[50]$} \\
\hline & TACE & Resolved & 2009 & {$[50]$} \\
\hline & SOR & Died & 2009 & {$[51]$} \\
\hline & SOR & Resolved & 2010 & {$[52]$} \\
\hline & SOR & Resolved & 2010 & [53] \\
\hline
\end{tabular}


Table 1: Continued.

\begin{tabular}{|c|c|c|c|c|}
\hline Tumor type & Treatment & Outcome of TLS & $\begin{array}{c}\text { Year } \\
\text { published }\end{array}$ & Reference \\
\hline \multirow{3}{*}{ Renal carcinoma } & SUN & Resolved & 2007 & {$[54]$} \\
\hline & SUN & Resolved & 2010 & {$[55]$} \\
\hline & SUN & ?? & 2011 & {$[56]$} \\
\hline Transitional cell carcinoma & GC & Died & 2007 & {$[57]$} \\
\hline \multirow{4}{*}{ Prostate cancer } & DTX & Died & 2004 & {$[58]$} \\
\hline & $\mathrm{CAB}$ & Died & 2004 & {$[59]$} \\
\hline & PTX & Resolved & 2005 & {$[60]$} \\
\hline & $\mathrm{CAB}$ & Died & 2007 & {$[61]$} \\
\hline \multirow{10}{*}{ Breast carcinoma } & $\mathrm{TX}$ & Resolved & 1986 & {$[62]$} \\
\hline & 5-FU, DOXO, CTX & Died & 1987 & {$[63]$} \\
\hline & CTX, MTX, 5-FU & Resolved & 1989 & {$[64]$} \\
\hline & MIT & Resolved & 1994 & {$[65]$} \\
\hline & None & Died & 1995 & {$[16]$} \\
\hline & PTX & Died & 1997 & {$[66]$} \\
\hline & $\mathrm{RT}$ & Died & 2000 & {$[67]$} \\
\hline & CAP & Died & 2004 & {$[68]$} \\
\hline & 5-FU, EPR, CTX & Resolved & 2005 & {$[30]$} \\
\hline & GC, CDDP & Resolved & 2005 & {$[30]$} \\
\hline \multirow{2}{*}{ Ovarian cancer } & CBCDA, CTX & Resolved & 1993 & {$[69]$} \\
\hline & TOPO & Resolved & 2005 & {$[70]$} \\
\hline Endometrial cancer & CBCDA, PTX & Died & 2010 & [71] \\
\hline \multirow{2}{*}{ Vulvar carcinoma } & CDDP, 5-FU & Resolved & 1993 & {$[72]$} \\
\hline & CDDP, 5-FU & Died & 1998 & {$[73]$} \\
\hline \multirow{2}{*}{ Thymoma } & CDDP, DOXO, CS & Resolved & 1997 & {$[74]$} \\
\hline & $\mathrm{S}$ & Resolved & 2004 & {$[75]$} \\
\hline \multirow{7}{*}{ Melanoma } & TNF-alpha, mAb & Died & 1994 & {$[76]$} \\
\hline & $\begin{array}{c}\text { IL-1, IF-alpha, CDDP. VIN, } \\
\text { DTIC }\end{array}$ & Resolved & 1999 & [77] \\
\hline & CDDP, DTIC, IF-alpha & Died & 2001 & {$[78]$} \\
\hline & CS & Resolved & 2002 & {$[79]$} \\
\hline & $\begin{array}{c}\text { CDDP, VIN, DTIC, IF-alpha, } \\
\text { IL-2 }\end{array}$ & Resolved & 2004 & {$[80]$} \\
\hline & TAI-CDDP & Resolved & 2009 & {$[81]$} \\
\hline & CS & Died & 2009 & {$[82]$} \\
\hline Gestational trophoblastic neoplasia & VP-16, MTX, DACT, CTX, VCR & Resolved & 2010 & {$[83]$} \\
\hline \multirow{8}{*}{ Germ cell tumor } & VIN, BL & Resolved & 1989 & {$[64]$} \\
\hline & CDDP, VP-16, BL & Resolved & 2000 & {$[84]$} \\
\hline & None & Resolved & 2001 & {$[17]$} \\
\hline & None & Resolved & 2001 & [17] \\
\hline & BL, VP-16, CDDP & Died & 2008 & {$[85]$} \\
\hline & VP-16, CBCDA & Resolved & 2008 & {$[85]$} \\
\hline & VP-16, CBCDA & Died & 2008 & {$[85]$} \\
\hline & None & Died & 2010 & {$[18]$} \\
\hline \multirow{5}{*}{ Neuroblastoma } & VCR, TN, RT & Resolved & 1994 & {$[86]$} \\
\hline & $\mathrm{RT}$ & Resolved & 1994 & {$[86]$} \\
\hline & VCR, TN, RT & Resolved & 1994 & {$[86]$} \\
\hline & CTX, TN & Resolved & 1994 & {$[86]$} \\
\hline & CTX, DOXO, VCR & Resolved & 2003 & [87] \\
\hline
\end{tabular}


TABle 1: Continued.

\begin{tabular}{|c|c|c|c|c|}
\hline Tumor type & Treatment & Outcome of TLS & $\begin{array}{c}\text { Year } \\
\text { published }\end{array}$ & Reference \\
\hline \multirow{2}{*}{ Medulloblastoma } & RT & Resolved & 1984 & {$[88]$} \\
\hline & CDDP, VP-16 & Resolved & 2003 & [89] \\
\hline \multirow{6}{*}{ Sarcoma } & CTX, ALT & Resolved & 1993 & [90] \\
\hline & CBCDA, EPR, VCR & Resolved & 1993 & {$[91]$} \\
\hline & CDDP, A, DTIC & Resolved & 2009 & {$[92]$} \\
\hline & None & Resolved & 2010 & [19] \\
\hline & None & Resolved & 2010 & {$[19]$} \\
\hline & VCR, ACT-D, CTX & Resolved & 2011 & [93] \\
\hline Total & & $\begin{array}{c}\text { D: 41; R: } 58 ; \\
\text { ??: } 1\end{array}$ & 100 & \\
\hline \multicolumn{5}{|c|}{ 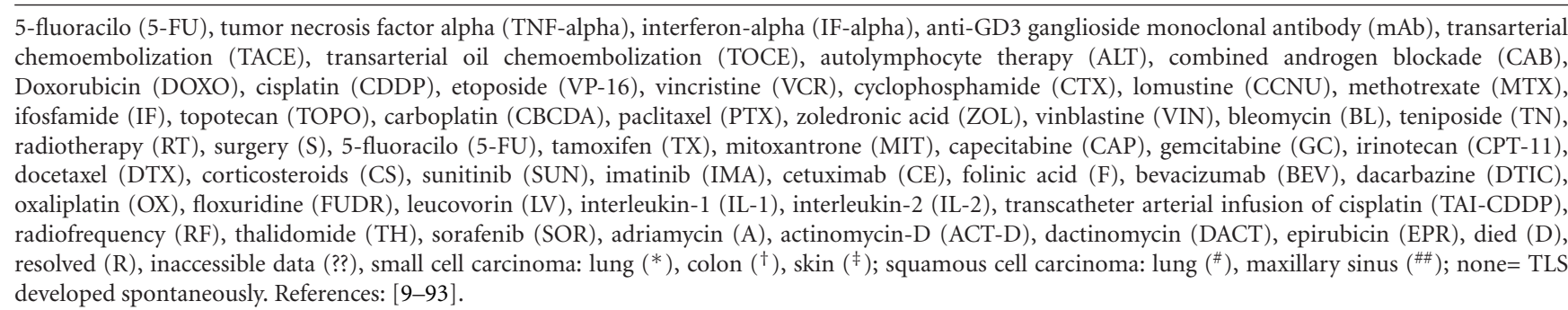 } \\
\hline
\end{tabular}

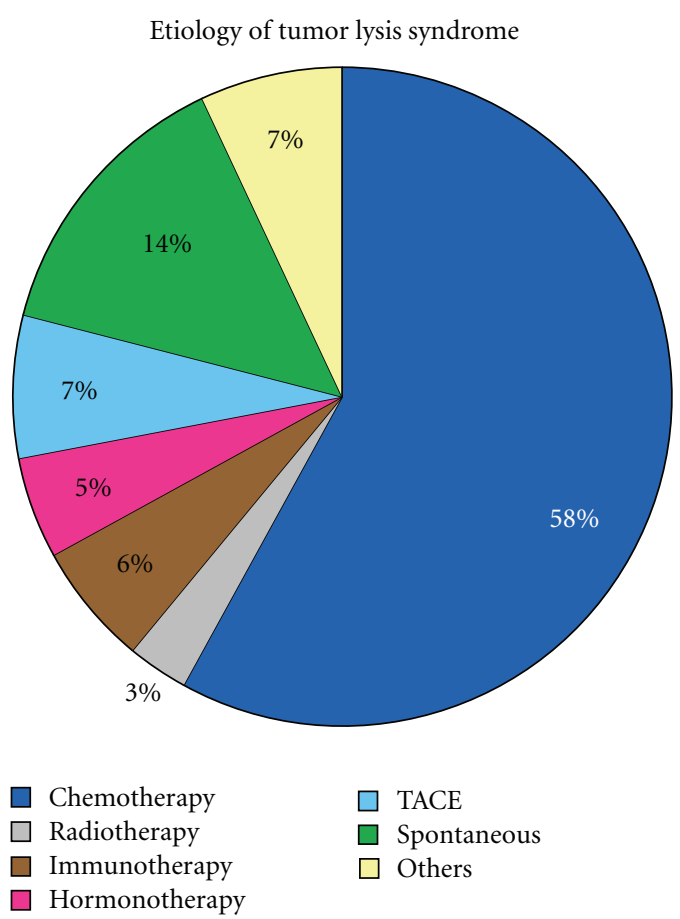

FIgUre 1: Etiology of tumor lysis syndrome. TACE: transarterial chemoembolization. Others include surgery, bisphosphonates, radiofrequency, combination of different cancer therapies.

$1,8,15)$, floxuridine $(110 \mathrm{mg} / \mathrm{kg}$ i.v. over 24 hours on days 1 , $8,15)$, and leucovorin calcium $\left(500 \mathrm{mg} / \mathrm{m}^{2}\right.$ i.v. over 24 hours on days $1,8,15)$ with treatment repeated every 4 weeks. After the second course (January 2007), he underwent resective therapy (partial gastrectomy) followed by 2 more cycles of the above-mentioned chemotherapy regimen as an adjuvant therapy.

Five months later, recurrence of the primary tumor was found in the liver; therefore, the patient was started on a different regimen (paclitaxel $120 \mathrm{mg} / \mathrm{m}^{2}$, floxuridine $150 \mathrm{mg} / \mathrm{kg}$, leucovorin $500 \mathrm{mg} / \mathrm{m}^{2}$, and cisplatin $100 \mathrm{mg} /$ $\mathrm{m}^{2}$ ), and liver segmentectomy was performed.

Unfortunately, patient failed regular controls, and by 2011 a CT of the chest and abdomen revealed extensive metastatic liver nodules which ranged from $3.5 \mathrm{~cm}$ to subcentimeter in size, and metastasis to the sternum were also found. Consequently, he was again included in the initial experimental chemotherapy regimen as a first line therapy for his metastatic disease (oxaliplatin, docetaxel, floxuridine, and leucovorin).

Seven days after receiving the first chemotherapy cycle, he developed nausea, vomiting, oliguria, generalized weakness, and was referred to the emergency department by his oncologist due to abnormal laboratory data (Table 2).

On arrival the patient was alert and appeared in poor general condition, pale, volume depleted with low blood pressure $(102 / 63 \mathrm{mmHg})$, tachycardia $(102 / \mathrm{min})$, respiratory rate of $20 / \mathrm{min}$, and body temperature of $36.6^{\circ} \mathrm{C}$. A firm, nontender, $2 \mathrm{~cm}$ below the costal margin of the right midclavicular line hepatomegaly was appreciated. There was no peripheral lymphadenopathy, and laboratory findings are shown on Table 2.

Urinalysis determined urine $\mathrm{pH}$ of 5.0 (4.5-7.5). The chest radiograph appeared to be normal. An EKG demonstrated atrial fibrillation with rapid ventricular response, left anterior fascicular block, and peaked T waves (Figure 3). A renal ultrasound examination revealed an increased bilateral cortical echogenicity but no evidence of hydronephrosis. 
TABLE 2: Laboratory values before and after chemotherapy.

\begin{tabular}{|c|c|c|c|c|}
\hline Parameters & Normal ranges & Patient's baseline & $\begin{array}{l}\text { Abnormal data for which } \\
\text { patient was referred to ER* }\end{array}$ & At ER* \\
\hline Leukocytes $\left(/ \mathrm{mm}^{3}\right)$ & $4,500-11,000$ & 12,000 & 6,500 & 7,400 \\
\hline Hemoglobin (g/dL) & $14-18$ & 11 & 8.6 & 9.6 \\
\hline Hematocrit (\%) & $42-52$ & 34 & 26.9 & 30 \\
\hline Platelets $\left(/ \mathrm{mm}^{3}\right)$ & $150,000-400,000$ & 327,000 & 39,000 & 37,000 \\
\hline Glucose (mg/dL) & $74-106$ & 86 & 95 & 104 \\
\hline Sodium (mEq/L) & $135-147$ & 138 & 130 & 127 \\
\hline Potassium (mEq/L) & $3.5-5$ & 4 & 8.4 & 8.7 \\
\hline Phosphorus (mg/dL) & $3.0-4.5$ & - & - & 13.9 \\
\hline Calcium (mg/dL) & $8.4-10.2$ & 8.4 & 5.4 & 5.4 \\
\hline Uric acid (mg/dL) & $3.0-8.2$ & 4.3 & 17.8 & 17.6 \\
\hline BUN (mg/dL) & $9-20$ & 18 & 175 & 183 \\
\hline Creatinine $(\mathrm{mg} / \mathrm{dL})$ & $0.8-1.5$ & 1.00 & 15.4 & 14.98 \\
\hline Total bilirubin $(\mathrm{mg} / \mathrm{dL})$ & $0.2-1.3$ & 0.5 & 0.8 & 0.7 \\
\hline Alkaline phosphatase (U/L) & $38-126$ & 381 & 235 & 254 \\
\hline AST/ALT (U/L) & $15-46 / 21-72$ & $48 / 30$ & $44 / 53$ & $46 / 58$ \\
\hline eGFR (mL/min) & $>60$ & $>60$ & 3 & 3 \\
\hline $\mathrm{LDH}(\mathrm{U} / \mathrm{L})$ & $0-250$ & 9,027 & - & - \\
\hline $\mathrm{pH}$ & $7.35-7.45$ & - & - & 7.17 \\
\hline $\mathrm{PaCO} 2$ (mmHg) & $33-44$ & - & - & 28 \\
\hline Bicarbonate $(\mathrm{mEq} / \mathrm{L})$ & $22-28$ & - & - & 10 \\
\hline
\end{tabular}

BUN: blood urea nitrogen; AST: aspartate aminotransferase; ALT: alanine aminotransferase; LDH: lactate dehydrogenase. ${ }^{*} 7$ days after chemotherapy.

A diagnosis of chemotherapy-induced TLS with acute renal failure was made. The patient was given vigorous volume expansion, intravenous sodium bicarbonate, calcium gluconate, insulin given together with $50 \%$ dextrose, and allopurinol. His laboratory data did not improve and hemodialysis was started. The patient underwent a total of 6 hemodialysis over a course of two weeks and was discharged 18 days after with normal serum electrolyte and metabolic parameters. However, his renal function continued to be impaired with a serum creatinine of $3.86 \mathrm{mg} / \mathrm{dL}$, blood urea nitrogen of $23 \mathrm{mg} / \mathrm{dL}$, and eGFR of 16.

\section{Review of the Literature}

TLS is an oncologic emergency characterized by severe electrolyte and metabolic abnormalities due to a rapid and massive lysis of malignant cells with the release of intracellular contents into the bloodstream, overwhelming the excretory and reutilization capacities of the body, leading to hyperuricemia, hyperkalemia, hyperphosphatemia, and secondary hypocalcemia [1-8]. As a consequence, these biochemical disorders can become clinically relevant and present as renal insufficiency, cardiac arrhythmias, seizures, and death due to multiorgan failure [1-8]. Cairo and Bishop published the most complete and often referenced definition of TLS in 2004. They classified TLS into two groups, separating patients exhibiting only laboratory findings of TLS from those with potentially life-threatening clinical presentations. Cairo and Bishop definitions of laboratory and clinical TLS are summarized in Table $3[1-4,6,7]$.

In the setting of a malignancy with a high proliferation rate, large tumor burden, and/or high sensitivity to treatment, initiation of anticancer treatment, such as chemotherapy, radiotherapy, resective surgical procedures, immunotherapy, hormonotherapy, radiofrequency ablation, or sometimes glucocorticoid therapy alone may result in the rapid lysis of tumor cells [1, 5-8] (Table 1) (Figure 1). In addition, TLS can occur spontaneously from the tumor necrosis prior the onset of anticancer therapy [1,4-19] (Table 1) (Figure 1).

Tumor and host-related factors associated with an increased risk of TLS in solid tumors are mentioned in Table 4 [1-8]. The tumor-related risk factors are common characteristics of hematological malignancies, where TLS is a well-known clinical problem, especially in acute lymphoblastic leukemias and high-grade non-Hodgkin's lymphomas, and particularly in Burkitt's lymphoma [1-7]. However, TLS can rarely occur in solid tumors that have a high proliferative rate, large tumor burden, and high sensitivity to cytotoxic therapy $[1,4,6]$.

According to the literature review, there have been 100 reported cases of TLS in patients with solid tumors from the first report in 1977 to 2011 (Table 1) (Figure 2), including small cell carcinomas $[9,20-30]$, squamous cell carcinomas $[10,11]$, adenocarcinomas of the lung $[12,31-33]$, mixed small cell and nonsmall cell lung carcinoma [34], gastrointestinal carcinomas [13-15, 35-42], hepatoblastomas 
TABle 3: Classification of tumor lysis syndrome by Cairo and Bishop.

\begin{tabular}{|c|c|c|c|c|}
\hline $\begin{array}{l}\text { Laboratory TLS } \\
\text { (LTLS) }\end{array}$ & Uric acid $\geq 8.0 \mathrm{mg} / \mathrm{dL}$ & Phosphorus $\geq 4.5 \mathrm{mg} / \mathrm{dL}$ & Potassium $\geq 6.0 \mathrm{mmol} / \mathrm{L}$ & $\begin{array}{c}\text { Calcium } \leq 7.0 \mathrm{mg} / \mathrm{dL} \text { or } \\
\text { ionized calcium }<1.12\end{array}$ \\
\hline $\begin{array}{l}\text { Clinical TLS } \\
\text { (CTLS) }\end{array}$ & Acute renal failure & Cardiac arrhythmia & Seizure & Sudden death \\
\hline
\end{tabular}

References: $[1-4,6,7]$.

TABLE 4: Risk factors for tumor lysis syndrome is solid tumors.

\begin{tabular}{|c|c|c|c|}
\hline & Tumor-related factors & & Host-related factors \\
\hline Tumor extension & Cell lysis potential & $\begin{array}{l}\text { Pretreatment laboratory } \\
\text { findings }\end{array}$ & \multirow{2}{*}{$\begin{array}{l}\text { (i) Low urinary flow } \\
\text { (ii) Dehydration and/or } \\
\text { inadequate hydration } \\
\text { (iii) Preexisting } \\
\text { nephropathy* } \\
\text { (iv) Exposure to } \\
\text { nephrotoxins } \\
\text { (v) Hypotension } \\
\text { (vi) Obstructive } \\
\text { uropathy }\end{array}$} \\
\hline $\begin{array}{l}\text { (i) Large tumor burden } \\
\text { (ii) Bulky tumor }(\geq 10 \mathrm{~cm}) \\
\text { (iii) Extensive metastasis } \wedge \\
\text { (iv) Extrinsic compression of } \\
\text { the genitourinary tract by the } \\
\text { tumor }\end{array}$ & $\begin{array}{l}\text { (i) High proliferative } \\
\text { rate } \\
\text { (ii) High sensitivity to } \\
\text { anticancer therapy } \\
\text { (iii)Type and intensity of } \\
\text { initial anticancer therapy } \\
\text { (using a combination of } \\
\text { multiple } \\
\text { chemotherapists) }\end{array}$ & $\begin{array}{l}\text { (i) Elevated LDH } \\
\text { (ii) Elevated serum } \\
\text { creatinine } \\
\text { (iii) Elevated serum uric } \\
\text { acid } \\
\text { (iv) Elevated serum } \\
\text { phosphate }\end{array}$ & \\
\hline
\end{tabular}

LDH: lactate dehydrogenase. ${ }^{\wedge}$ hepatomegaly, splenomegaly, and nephromegaly due to metastasis. Bone marrow infiltration. ${ }^{*}$ A patient with preexisting nephropathy from hypertension, diabetes, gout, or other causes is at greater risk for developing acute kidney injury and TLS. References: [1-8].

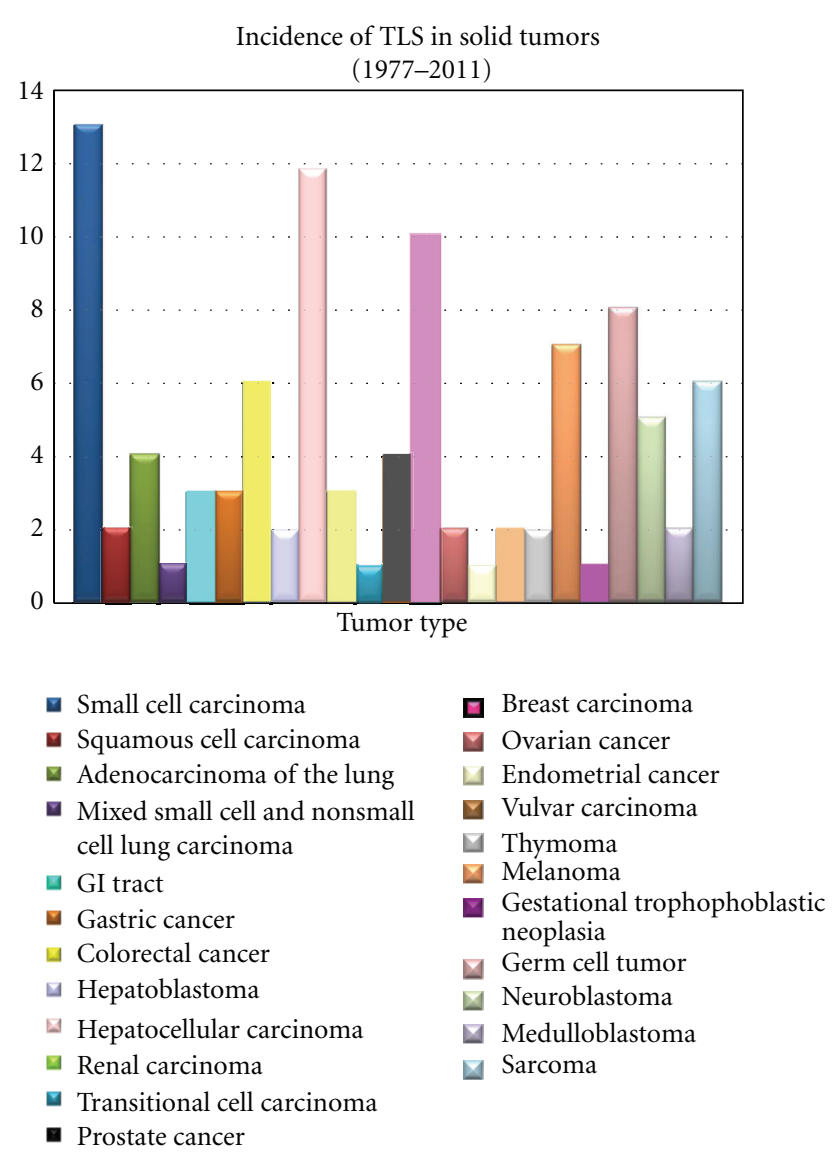

FIGURE 2: Reported cases of tumor lysis syndrome in solid tumors.

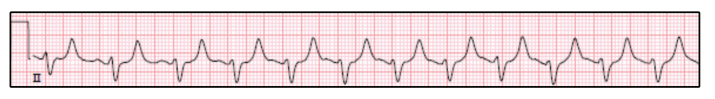

FIGURE 3: EKG from the patient's admission showing atrial fibrillation with rapid ventricular response and peaked $\mathrm{T}$ waves.

$[43,44]$, hepatocellular carcinomas $[15,45-53]$, renal carcinomas [54-56], transitional cell carcinoma [57], prostate carcinomas [58-61], breast carcinomas [16, 30, 62-68], ovarian carcinomas $[69,70]$, endometrial carcinoma [71], vulva carcinomas $[72,73]$, thymomas $[74,75]$, melanomas [76-82], gestational trophoblastic neoplasia [83], germ cell tumors [17, 18, 64, 84, 85], neuroblastomas [86, 87], medulloblastomas [88, 89], and sarcomas [19, 90-93]. Most cases regarded as TLS in solid tumors were chemotherapyinduced, even though various other causes were pointed out for TLS in solid tumors as well [3] (Table 1) (Figure 1). The dominant factor for developing TLS in solid tumors, which occurred in all 100 cases, was having a large tumor burden. Another relevant fact was the presence of metastatic disease observed in $83 \%$ of all cases, of which the liver was the most affected organ; thus, the remaining $17 \%$ presented with bulky primary tumor.

Other risk factors for developing TLS in solid tumors included pretreatment increased LDH, renal impairment, hyperuricemia, and hyperphosphatemia found in $86 \%$ (43/50), $26 \%$ (18/69), $42 \%$ (21/50), and $14 \%(6 / 44)$ of the evaluable patients in which specific results were reported, respectively. 
In $7 \%$ of the cases, we found hydronephrosis as a high risk for developing TLS due to compression of the genitourinary tract by the tumor, being particular hazard neoplasms such as germ cell tumor, prostate cancer, retroperitoneal sarcoma, and uterus carcinoma.

Irrespective of the cancer type, there is a $20-50 \%$ increase in mortality for undiagnosed or late-diagnosed TLS cases in solid tumors [8]. This high mortality rate may be due to the fact that in solid tumors, contrary to what is observed in hematological malignancies, TLS is usually evident after a few days within treatment when the patient may have already left the hospital $[3,8]$. Another cause is that in hematological malignancies, prophylactic measures are more often implemented, and awareness of the syndrome is higher. The fatality rate of the 100 cases presenting TLS in solid tumors was found to be $41 \%$.

Symptoms associated with TLS strongly reveal electrolyte and metabolic irregularities, which are hyperkalemia, hyperphosphatemia, secondary hypocalcemia, and hyperuricemia [1-8]. Hyperkalemia, which takes place within 12 to 24 hours from the antineoplastic treatment's initiation, becomes the earliest and most severe laboratory finding [3]. The clinical manifestations for hyperkalemia include lethargy, weakness, paresthesias, muscle cramps, nausea, vomiting, and abnormalities in the electrocardiogram, such as peaked $\mathrm{T}$ waves, prolonged PR interval, widened QRS complexes, ventricular tachycardia, ventricular fibrillation, or asystole [2-5]. Since the phosphorus concentration is higher in malignant cells than in normal cells $(4: 1)$, accelerated tumor breakdown usually leads to hyperphosphatemia with the subsequent secondary hypocalcemia [1, 3-7]. Both electrolyte disturbances, hyperphosphatemia and hypocalcemia, may cause a variety of symptoms, such as nausea, vomiting, lethargy, muscle cramps, tetany, seizures, cardiac arrhythmias, and/or acute renal failure [2-6]. Accumulation of uric acid may increase the urinary uric acid concentration to a point where precipitation occurs, and acute renal failure may be the consequence. The widespread use of agents lowering uric acid production or excretion is responsible for nephrocalcinosis, becoming a major mechanism of acute renal failure in TLS $[1-3,6]$. However, calcium phosphate precipitation does not only occur in the kidneys, but also in other soft tissues such as the heart, where it may induce cardiac arrhythmias $[1-3,6]$.

The fact that urine is acidic facilitates uric acid to precipitate, thus excessive overproduction and over excretion could accumulate uric acid in the form of crystal precipitation in the renal tubules, leading to obstructive uropathy with acute kidney injury $[1,2,4,5,8,65]$. Uric acid or calcium phosphate accumulation does not always imply urinary tract symptoms; however, flank pain due to renal pelvic or ureteral stone formation may occur $[1,4]$. The urinalysis quite often discloses a number of uric acid crystals, amorphous urates, calcium phosphate crystals, and/or hematuria $[1,4]$.

The treatment principles for TLS are prevention, early diagnosis, and proper management of disorders [3]. In 2008, an international expert panel published evidencebased guidelines, for the prevention and treatment of TLS depending on the malignancy risk category. According to this evidence-based guidelines unless tumor and/or hostrelated risk factors are associated, solid tumors are considered low risk $(<1 \%)$ for developing TLS. Thus, adequate recommendations for the prevention and management of TLS in solid tumors are accurate hydration prior to therapy and a "watch and wait" approach with close monitoring on looking for the first biologic derangements characterizing TLS (hyperuricemia, hyperphosphatemia, hypocalcemia, increased creatinine level) without any form of prophylactic hypouricemic therapy or phosphate binders $[1-3,6,37]$.

Once TLS is established, the standard therapy strategy for treating TLS is based on volume expansion, decreasing the metabolic abnormalities, and in most cases providing supportive treatment of renal failure $[1,5,8]$.

Administration of fluids is important because it increases renal blood flow, glomerular filtration, and reduces the urinary supersaturation of uric acid, calcium, and phosphate $[2$, $4,5,7]$. Patients should receive $3 \mathrm{l} / \mathrm{m}^{2} /$ day $(200 \mathrm{~mL} / \mathrm{Kg} /$ day if $\leq 10 \mathrm{~kg})$ and have a urine output $\geq 100 \mathrm{~mL} / \mathrm{m}^{2} / \mathrm{h}(3 \mathrm{~mL} / \mathrm{kg} / \mathrm{h}$ if $\leq 10 \mathrm{~kg})[2-4,6]$. In the absence of obstructive uropathy and/or hypovolemia, diuretics may be used to maintain the adequate urine output $[2-4,6,7]$. The utility of lowdose dopamine to enhance renal blood flow is not as clear [3].

Maintaining urine $\mathrm{pH}$ above 7 with the aid of acetazolamide and/or sodium bicarbonate for the prevention and/or treatment of TLS may reduce the precipitation of uric acid crystals but at the same time may decrease the solubility of calcium phosphate or xanthine, and in the setting of acute renal failure, metabolic alkalosis may be an unintended consequence $[1,3,4,6,7]$. Consequently, the use of sodium bicarbonate should be restricted to those patients with severe metabolic acidosis [1].

Hyperkalemia may be an acute life-threatening emergency in patients with TLS. In case of hyperkalemia, cardiac membrane stabilization with $10 \%$ calcium gluconate may not be effective in the setting of severe hyperphosphatemia, and given an increased risk of calcium phosphate tissue precipitation, calcium administration is only appropriate for symptomatic hypocalcemia (arrhythmia, hypotension, tetany, or muscle cramps) [1,7]. Consequently, measures to reduce serum potassium or enhance potassium excretion should have priority. These include primarily insulin and beta- 2 agonists to shift potassium into cells and volume expansion and loop diuretics to enhance potassium elimination. Sodium bicarbonate may be used as a slow continuous infusion in the face of severe acidosis. Exchange resins may be administered but should not be relied upon in the setting of acute hyperkalemia due to their unpredictable efficacy. For patients with renal failure, dialysis should be initiated as soon as possible [1-7]. For hyperphosphatemia, phosphate binders and/or hypertonic dextrose with insulin may be used [1-7].

Allopurinol is a competitive inhibitor of xanthine oxidase (Figure 4), and it has been successfully prescribed for the treatment of hyperuricemia. Allopurinol is metabolized to oxypurinol, which in turn inhibits xanthine oxidase; therefore, it blocks the metabolic process of xanthine and hypoxanthine to uric acid, leading to an increase in the 
TABLE 5: Similarities and differences between chemotherapy-induced TLS in advanced gastric adenocarcinoma reported in 2008 and our case.

\begin{tabular}{|c|c|c|c|}
\hline Similarities & & Differences & \\
\hline \multirow{8}{*}{$\begin{array}{l}\text { (i) Massive liver metastasis } \\
\text { (ii) Elevated pretreatment } \\
\text { LDH } \\
\text { (iii) Large tumor burden } \\
\text {-Outcome of TLS: resolved }\end{array}$} & Characteristics & 2008 case & Actual case \\
\hline & Histology & Poorly differentiated & Moderately differentiated \\
\hline & Tumor extension & Primary bulky tumor is present & $\begin{array}{c}\text { Primary tumor was not } \\
\text { present (previously resected) }\end{array}$ \\
\hline & Pretreatment laboratory data & $\begin{array}{l}\text { Slightly elevated serum uric } \\
\text { acid }\end{array}$ & - \\
\hline & & Elevated serum phosphate & \\
\hline & $\begin{array}{c}\text { Host-related risk factors for } \\
\text { developing TLS }\end{array}$ & - & Dehydration \\
\hline & Chemotherapy regimen & Capecitabine and cisplatin & $\begin{array}{l}\text { Oxaliplatin, leucovorin, } \\
\text { floxuridine, and docetaxel }\end{array}$ \\
\hline & $\begin{array}{l}\text { Onset of TLS after receiving } \\
\text { chemotherapy }\end{array}$ & 3 days & 7 days \\
\hline
\end{tabular}

Reference: [37].

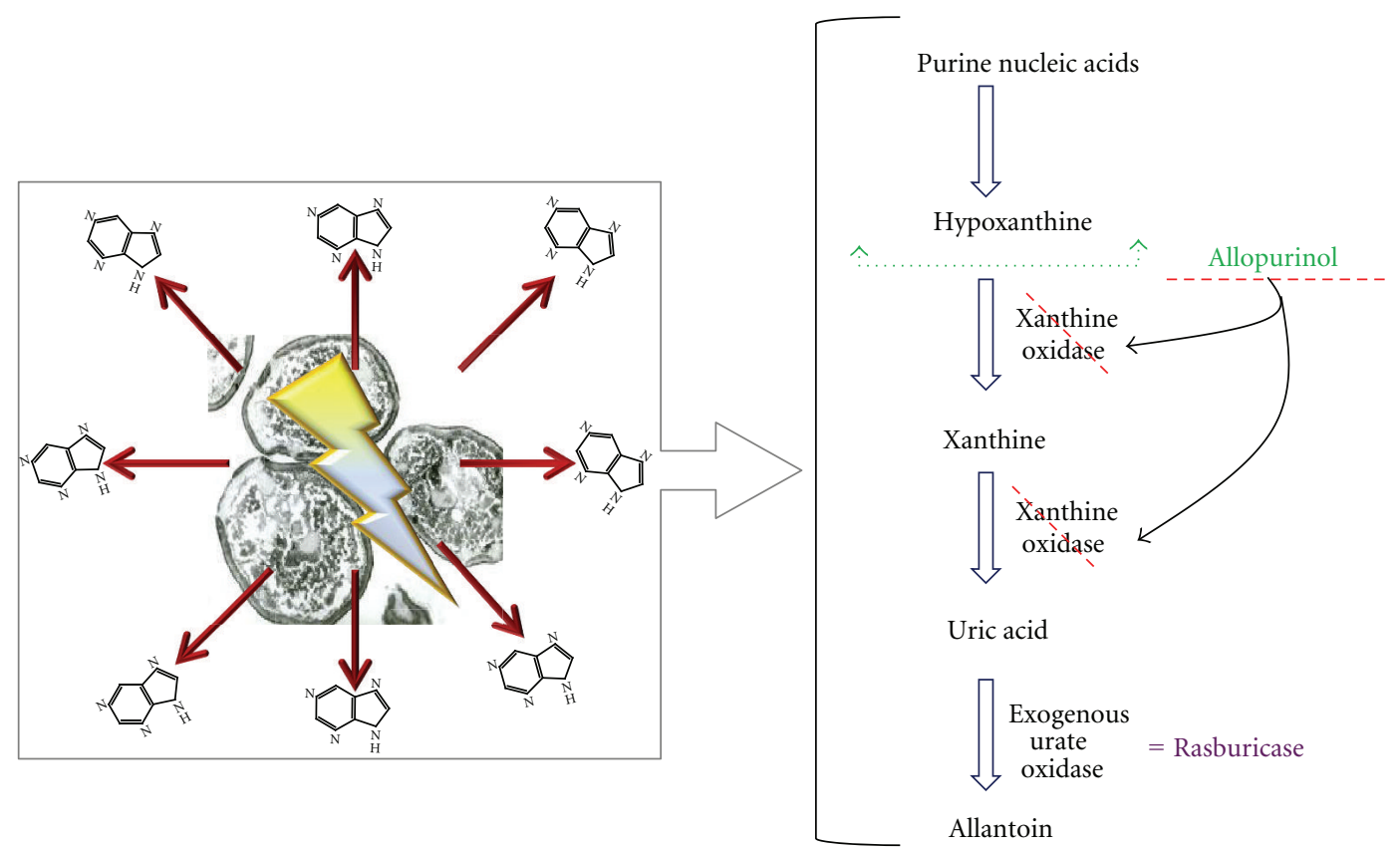

FIGURE 4: Mechanism of action of hypouricemic agents. Hyperuricemia is a consequence of the catabolism of purine nucleic acids to hypoxanthine and xanthine and then to uric acid via the enzyme xanthine oxidase. Allopurinol is a competitive inhibitor of the enzyme xanthine oxydase. Rasburicase (exogenous urate oxidase) leads uric acid to a more soluble compound, allantoin.

levels of these two metabolites [1,3-6]. As a result, patients with massive TLS who have been prescribed allopurinol may develop xanthine precipitation leading to acute renal failure $[1,2,4,5,7,65]$. This can be avoided by replacing allopurinol with urate oxidase, which catabolizes uric acid to the more soluble compound allantoin [1-6] (Figure 4). Urate oxidase is an enzyme that can be found in many mammals except humans $[1,3,4,6]$. The two available commercial forms of urate oxidase are a nonrecombinant form (uricozyme) and a recombinant form (rasburicase), which is the preferred one. Rasburicase has been shown to be more effective than allopurinol, since it has higher uricolytic effect [1, 3-7], it does not increase xanthine levels $[1,2,4,5,7]$, and it reduces high uric acid levels prior treatment initiation [1-7].

In some patients, despite prophylactic and therapeutic measures, acute renal failure ensues, and its management includes careful monitoring of fluid intake and output, electrolyte balance, hypertension control [4], and renal dialysis [94]. Indications for renal replacement therapy include volume overload with pulmonary edema or hypertension that is refractory to therapy, low urine output (oliguria), persistent or symptomatic hyperkalemia, hyperphosphatemia, hypocalcemia, and/or hyperuricemia despite conservative measures, metabolic acidosis with $\mathrm{pH}$ less 
than 7.2 or bicarbonate less than $10 \mathrm{mEq} / \mathrm{l}$, rapidly rising blood urea nitrogen greater than $150 \mathrm{mg} / \mathrm{dL}$, and neurologic symptoms secondary to uremia or electrolyte imbalance [4, 95]. From the above-mentioned criteria, oliguria and other biochemical disturbances related to TLS have become more frequent indications for dialysis than hyperuricemia since the introduction of rasburicase [2, 94]. Both hemodialysis and hemofiltration are affective, while peritoneal dialysis is not $[94,96]$. Dialysis should be continued until proper renal function is reestablished.

\section{Discussion}

Our patient with metastatic gastric adenocarcinoma developed metabolic (hyperkalemia, hyperuricemia, hyperphosphatemia, and hypocalcemia) and clinical (cardiac arrhythmia and acute renal failure) derangements 7 days after instituting chemotherapy, meeting CTLS diagnostic criteria. According to previous reports, there are 2 patients with advanced gastric adenocarcinomas who developed TLS documented in the literature $(34,35)$, although only one occurred after chemotherapy [37] (Table 5). Therefore, our case would be the second gastric adenocarcinoma chemotherapy-induced TLS but the first to be reported after the use of the experimental chemotherapeutic regimen consisting on oxaliplatin, leucovorin, floxuridine, and docetaxel.

Chemotherapy-related nephrotoxicity was less likely due to the fact that the anticancer agents the patient was receiving are not considered to be nephrotoxic, except for oxaliplatin and docetaxel which have less than a $1 \%$ probability of causing renal failure, and it usually occurs with high doses and after repeated exposures.

Large tumor burden, multiple metastases to liver and bone, the use of combination chemotherapy drugs, pretreatment elevated $\mathrm{LDH}$, and dehydration were the risk factors that placed the patient in a high-risk group for developing TLS [1-8], although his renal function and uric acid levels were normal before getting anticancer treatment.

The purpose for giving sodium bicarbonate to the patient was to correct the metabolic acidosis, rather than alkalinizing urine. Despite intensive medical treatment, the patient developed refractory electrolyte imbalances, metabolic acidosis, uremia, and oliguria. Thus, hemodialysis was performed with an improvement of the mentioned abnormalities, and the TLS was resolved. However, his renal function never returned to baseline, which has been linked to increased morbidity and mortality.

Even though solid tumors with high sensitivty to therapy are considered to be at high risk for developing TLS, we noticed that the syndrome was also present in tumor types considered as relatively insensitive to therapy such as melanoma, sarcoma, hepatocellular carcinoma, vulvar carcinoma, non-small cell lung cancer, and gastric cancer. According to our observations, the predominant risk factors to induce TLS in solid tumors are large tumor burden and liver metastases, rather than tumor sensitivity to therapy agents.
Liver metastases in solid tumors were found in most TLS cases, regardless whether patients had liver function abnormalities or not [3]. Apparently, liver involvement creates a risk for the development of TLS in solid malignancies, possible causes being high purine pools, increased tumor burden, and/or impaired uric acid metabolism [3].

\section{Conclusion}

Even though TLS in solid tumors is a rare condition, physicians should be aware of it, especially in therapy-sensitive large burden tumors with metastatic disease, increased pretreatment $\mathrm{LDH}$, renal impairment, hyperuricemia, and hyperphosphatemia, all of which are here documented to be mayor risk factors for the development of TLS.

If there is a possibility to develop TLS, the metabolic abnormalities should always be corrected before starting an anticancer regimen, since prevention is the best way to reduce its high morbidity and mortality.

In conclusion, TLS in solid tumors requires special attention for its prevention, early diagnosis, and management due to its poor clinical course. Physicians should be alert since improvement in the anticancer treatment may increase the incidence of TLS in solid tumors.

\section{References}

[1] R. Larson and C. H. Pui, “Tumor lysis syndrome," 2011, http://www.uptodate.com/contents/tumor-lysis-syndrome? source $=$ search_result\&search $=$ tumor+lysis + syndrome\&selectedTitle $=1 \sim 58$.

[2] S. C. Howard, D. P. Jones, and C. H. Pui, "The tumor lysis syndrome," New England Journal of Medicine, vol. 364, no. 19, pp. 1844-1854, 2011.

[3] C. Gemici, "Tumour lysis syndrome in solid tumours," Clinical Oncology, vol. 18, no. 10, pp. 773-780, 2006.

[4] M. S. Cairo and M. Bishop, "Tumour lysis syndrome: new therapeutic strategies and classification," British Journal of Haematology, vol. 127, no. 1, pp. 3-11, 2004.

[5] M. B. Davidson, S. Thakkar, J. K. Hix, N. D. Bhandarkar, A. Wong, and M. J. Schreiber, "Pathophysiology, clinical consequences, and treatment of tumor lysis syndrome," American Journal of Medicine, vol. 116, no. 8, pp. 546-554, 2004.

[6] T. I. Mughal, A. A. Ejaz, J. R. Foringer, and B. Coiffier, "An integrated clinical approach for the identification, prevention, and treatment of tumor lysis syndrome," Cancer Treatment Reviews, vol. 36, no. 2, pp. 164-176, 2010.

[7] B. Coiffier, A. Altman, C. H. Pui, A. Younes, and M. S. Cairo, "Guidelines for the management of pediatric and adult tumor lysis syndrome: an evidence-based review," Journal of Clinical Oncology, vol. 26, no. 16, pp. 2767-2778, 2008.

[8] B. Coiffier, "Acute tumor lysis syndrome-a rare complication in the treatment of solid tumors," Onkologie, vol. 33, no. 10, pp. 498-499, 2010.

[9] B. Jallad, T. Hamdi, S. Latta, M. N. Alhosaini, F. Kheir, and N. Iroegbu, "Tumor lysis syndrome in small cell lung cancer: a case report and review of the literature," Onkologie, vol. 34, no. 3, pp. 129-131, 2011.

[10] C. Shenoy, "Acute spontaneous tumor lysis syndrome in a patient with squamous cell carcinoma of the lung," QJM, vol. 102, no. 1, pp. 71-73, 2009. 
[11] M. Abboud and A. Shamseddine, "Maxillary sinus squamous cell carcinoma presenting with fatal tumor lysis syndrome: a case report and review of the literature," Case Reports in Oncology, vol. 2, pp. 229-233, 2009.

[12] J. Feld, H. Mehta, and R. L. Burkes, "Acute spontaneous tumor lysis syndrome in adenocarcinoma of the lung: a case report," American Journal of Clinical Oncology, vol. 23, no. 5, pp. 491493, 2000.

[13] D. R. Crittenden and G. L. Ackerman, "Hyperuricemic acute renal failure in disseminated carcinoma," Archives of Internal Medicine, vol. 137, no. 1, pp. 97-99, 1977.

[14] I. S. Woo, J. S. Kim, M. J. Park et al., "Spontaneous acute tumor lysis syndrome with advanced gastric cancer," Journal of Korean Medical Science, vol. 16, no. 1, pp. 115-118, 2001.

[15] E. Vaisban, A. Braester, O. Mosenzon, M. Kolin, and Y. Horn, "Spontaneous tumor lysis syndrome in solid tumors: really a rare condition?" American Journal of the Medical Sciences, vol. 325, no. 1, pp. 38-40, 2003.

[16] N. T. Sklarin and M. Markham, "Spontaneous recurrent tumor lysis syndrome in breast cancer," American Journal of Clinical Oncology, vol. 18, no. 1, pp. 71-73, 1995.

[17] G. Pentheroudakis, V. O’Neill, P. Vasey, and S. Kaye, “Spontaneous acute tumour lysis syndrome in patients with metastatic germ cell tumours: report of two cases," Supportive Care in Cancer, vol. 9, no. 7, pp. 554-557, 2001.

[18] V. D’Alessandro, A. Greco, C. Clemente et al., "Severe spontaneous acute tumor lysis syndrome and hypoglycemia in patient with germ cell tumor," Tumori, vol. 96, no. 6, pp. 1040-1043, 2010.

[19] E. Bien, L. MacIejka-Kapuscinska, M. Niedzwiecki et al., "Childhood rhabdomyosarcoma metastatic to bone marrow presenting with disseminated intravascular coagulation and acute tumour lysis syndrome: review of the literature apropos of two cases," Clinical and Experimental Metastasis, vol. 27, no. 6, pp. 399-407, 2010.

[20] N. J. Vogelzang, R. A. Nelimark, and K. A. Nath, "Tumor lysis syndrome after induction chemotherapy of small-cell bronchogenic carcinoma," Journal of the American Medical Association, vol. 249, no. 4, pp. 513-514, 1983.

[21] M. A. Baumann, J. C. Frick, P. Y. Holoye, and N. J. Vogelzang, "The tumor lysis syndrome," Journal of the American Medical Association, vol. 250, no. 5, p. 615, 1983.

[22] N. Heching and P. Bonomi, "Tumor lysis syndrome in metastatic small cell cancer," Proceedings of the American Association for Cancer Research, vol. 29, p. 179, 1988.

[23] A. M. Hussein and L. G. Feun, "Tumor lysis syndrome after induction chemotherapy in small-cell lung carcinoma," American Journal of Clinical Oncology, vol. 13, no. 1, pp. 1013, 1990.

[24] L. Y. Dirix, A. Prove, D. Becquart, E. Wouters, P. Vermeulen, and A. Van Oosterom, "Tumor lysis syndrome in a patient with metastatic Merkel cell carcinoma," Cancer, vol. 67, no. 8 , pp. 2207-2210, 1991.

[25] T. Ohnishi, K. Mori et al., "Tumor lysis syndrome in widely metastasic small-cell lung cancer," International Journal of Clinical Oncology, vol. 2, pp. 235-237, 1997.

[26] G. P. Kalemkerian, B. Darwish, and M. L. Varterasian, "Tumor lysis syndrome in small cell carcinoma and other solid tumors," American Journal of Medicine, vol. 103, no. 5, pp. 363-367, 1997.

[27] M. A. Marinella, "Fatal tumor lysis syndrome and gastric hemorrhage associated with metastatic small-cell lung carcinoma," Medical and Pediatric Oncology, vol. 32, pp. 464-465, 1999.
[28] A. M. Kallab and A. P. Jillella, "Tumor lysis syndrome in small cell lung cancer," Medical Oncology, vol. 18, no. 2, pp. 149-151, 2001.

[29] S. Beriwal, S. Singh, and J. A. Garcia-Young, "Tumor lysis syndrome in extensive-stage small-cell lung cancer," American Journal of Clinical Oncology, vol. 25, no. 5, pp. 474-475, 2002.

[30] F. E. Mott, A. Esana et al., "Tumor lysis syndrome in solid tumors," Supportive Cancer Therapy, vol. 2, pp. 188-191, 2005.

[31] D. A. Persons, J. Garst, R. Vollmer, and J. Crawford, "Tumor lysis syndrome and acute renal failure after treatment of nonsmall-cell lung carcinoma with combination irinotecan and cisplatin," American Journal of Clinical Oncology, vol. 21, no. 4, pp. 426-429, 1998.

[32] M. Kurt, I. K. Onal, T. Elkiran, B. Altun, K. Altundag, and I. Gullu, "Acute tumor lysis syndrome triggered by zoledronic acid in a patient with metastatic lung adenocarcinoma," Medical Oncology, vol. 22, no. 2, pp. 203-206, 2005.

[33] D. Ajzensztejn, V. S. Hegde, and M. L. Siow, "Tumor lysis syndrome after treatment with docetaxel for non-small-cell lung cancer," Journal of Clinical Oncology, vol. 24, no. 15, pp. 2389-2391, 2006.

[34] H. H. Sewani and J. T. Rabatin, "Acute tumor lysis syndrome in a patient with mixed small cell and non-small cell tumor," Mayo Clinic Proceedings, vol. 77, no. 7, pp. 722-728, 2002.

[35] P. J. Saylor and T. R. Reid, "Tumor lysis syndrome after treatment of a gastrointestinal stromal tumor with the oral tyrosine kinase inhibitor sunitinib," Journal of Clinical Oncology, vol. 25, no. 23, pp. 3544-3546, 2007.

[36] E. M. Pinder, G. S. S. Atwal, A. A. Ayantunde et al., "Tumour lysis syndrome occurring in a patient with metastatic gastrointestinal stromal tumour treated with glivec (imatinib mesylate, gleevec, STI571)," Sarcoma, vol. 2007, Article ID 82012, 2007.

[37] H. S. Han, R. P. Sook, Y. K. Sun et al., "Tumor lysis syndrome after capecitabine plus cisplatin treatment in advanced gastric cancer," Journal of Clinical Oncology, vol. 26, no. 6, pp. 10061008, 2008.

[38] M. Boisseau, R. Bugat, and M. Mahjoubi, "Rapid tumour lysis syndrome in a metastatic colorectal cancer increased by treatment with irinotecan (CPT-11)," European Journal of Cancer, vol. 32, no. 4, pp. 737-738, 1996.

[39] Z. Nikolic-Tomasevic, S. Jelic, I. Popov, and D. Radosavljevic, "Irinotecan as second-line treatment in metastatic colorectal cancer: dilemmas regarding patient selection and toxicity prediction," Journal of Chemotherapy, vol. 12, no. 3, pp. 244251,2000

[40] I. Oztop, B. Demirkan, A. Yaren et al., "Rapid tumor lysis syndrome in a patient with metastatic colon cancer as a complication of treatment with 5-fluorouracil/leucoverin and irinotecan,” Tumori, vol. 90, no. 5, pp. 514-516, 2004.

[41] G. Krishnan, K. D'Silva, and A. Al-Janadi, "Cetuximab-related tumor lysis syndrome in metastatic colon carcinoma," Journal of Clinical Oncology, vol. 26, no. 14, pp. 2406-2408, 2008.

[42] M. Hentrich, X. Schiel et al., "Fatal tumor lysis syndrome after irinotecan/5-FU/folinic acid/bevacizumab-containig therapy in a patient heavily pretrated for metastasic colon cancer," Acta Oncologica, vol. 47, pp. 155-156, 2008.

[43] T. E. Lobe, M. S. Karkera, M. D. Custer, R. E. Shenefelt, and E. C. Douglass, "Fatal refractory hyperkalemia due to tumor lysis during primary resection for hepatoblastoma," Journal of Pediatric Surgery, vol. 25, no. 2, pp. 249-250, 1990.

[44] R. S. Bercovitz, B. S. Greffe, and S. P. Hunger, "Acute tumor lysis syndrome in a 7-month-old with hepatoblastoma," Current Opinion in Pediatrics, vol. 22, no. 1, pp. 113-116, 2010. 
[45] I. A. Burney, "Acute tumor lysis syndrome after transcatheter chemoembolization of hepatocellular carcinoma," Southern Medical Journal, vol. 91, no. 5, pp. 467-470, 1998.

[46] S. G. Lehner, J. E. Gould, W. E. A. Saad, and D. B. Brown, "Tumor lysis syndrome after radiofrequency ablation of hepatocellular carcinoma," American Journal of Roentgenology, vol. 185, no. 5, pp. 1307-1309, 2005.

[47] C. C. Lee, Y. H. Wu, S. H. Chung, and W. J. Chen, "Acute tumor lysis syndrome after thalidomide therapy in advanced hepatocellular carcinoma," Oncologist, vol. 11, no. 1, pp. 87$88,2006$.

[48] N. Sakamoto, S. Monzawa, H. Nagano et al., "Acute tumor lysis syndrome caused by transcatheter oily chemoembolization in a patient with a large hepatocellular carcinoma," Cardiovascular and Interventional Radiology, vol. 30, pp. 508-511, 2007.

[49] H. Shiba, Y. Ishida, S. Wakiyama, T. Sakamoto, T. Misawa, and K. Yanaga, "Acute tumor lysis syndrome after transarterial chemoembolization for hepatocellular carcinoma," Cancer Science, vol. 99, no. 10, pp. 2104-2105, 2008.

[50] P. M. Hsieh, K. C. Hung, and Y. S. Chen, "Tumor lysis syndrome after transarterial chemoembolization of hepatocellular carcinoma: case reports and literature review," World Journal of Gastroenterology, vol. 15, no. 37, pp. 4726-4728, 2009.

[51] W. S. Huang and C. H. Yang, "Sorafenib induced tumor lysis syndrome in an advanced hepatocellular carcinoma patient," World Journal of Gastroenterology, vol. 15, no. 35, pp. 44644466, 2009.

[52] K. Shiozawa, M. Watanabe, H. Takenaka et al., "Tumor lysis syndrome after sorafenib for hepatocellular carcinoma: a case report," Hepato-Gastroenterology, vol. 57, no. 101, pp. 688690, 2010.

[53] S. Joshita, K. Yoshizawa, K. Sano et al., "A patient with advanced hepatocellular carcinoma treated with sorafenib tosylate showed massive tumor lysis with avoidance of tumor lysis syndrome," Internal Medicine, vol. 49, no. 11, pp. 991994, 2010

[54] T. Nicholaou, R. Wong, and I. D. Davis, "Tumour lysis syndrome in a patient with renal-cell carcinoma treated with sunitinib malate," Lancet, vol. 369, no. 9577, pp. 1923-1924, 2007.

[55] J. Michels, N. Lassau, M. Gross-Goupil, C. Massard, A. Mejean, and B. Escudier, "Sunitinib inducing tumor lysis syndrome in a patient treated for renal carcinoma," Investigational New Drugs, vol. 28, no. 5, pp. 690-693, 2010.

[56] E. Rodriguez-Reimundes, F. Perazzo, and A. R. Vilches, "Tumor lysis syndrome in a patient with a renal carcinoma treated with sunitinib," Medicina, vol. 71, no. 2, pp. 158-160, 2011.

[57] C. J. Lin, K. H. Lim, Y. C. Cheng, H. H. Chen, and C. J. Wu, "Tumor lysis syndrome after treatment with gemcitabine for metastatic transitional cell carcinoma," Medical Oncology, vol. 24, no. 4, pp. 455-457, 2007.

[58] S. M. Sorscher, "Tumor lysis syndrome following docetaxel therapy for extensive metastatic prostate cancer," Cancer Chemotherapy and Pharmacology, vol. 54, pp. 191-192, 2004.

[59] T. Tanvetyanon and A. M. Choudhury, "Fatal acute tumor lysis syndrome, hepatic encephalopathy and flare phenomenon following combined androgen blockade," Journal of Urology, vol. 171, no. 4, p. 1627, 2004.

[60] J. L. Wright, D. W. Lin, P. Dewan, and R. B. Montgomery, "Tumor lysis syndrome in a patient with metastatic, androgen independent prostate cancer," International Journal of Urology, vol. 12, no. 11, pp. 1012-1013, 2005.
[61] C. J. Lin, R. K. Hsieh, K. H. Lim, H. H. Chen, Y. C. Cheng, and $\mathrm{C}$. J. Wu, "Fatal spontaneous tumor lysis syndrome in a patient with metastatic, androgen-independent prostate cancer," Southern Medical Journal, vol. 100, no. 9, pp. 916-917, 2007.

[62] P. Cech, J. B. Block, L. A. Cone, and R. Stone, "Tumor lysis syndrome after tamoxifen flare," New England Journal of Medicine, vol. 315, no. 4, pp. 263-264, 1986.

[63] M. E. Stark, M. C. D. Dyer, and C. J. Coonley, "Fatal acute tumor lysis syndrome with metastatic breast carcinoma," Cancer, vol. 60, no. 4, pp. 762-764, 1987.

[64] J. C. Barton, "Tumor lysis syndrome in nonhematopoietic neoplasms," Cancer, vol. 64, no. 3, pp. 738-740, 1989.

[65] P. Drakos, J. Bar-Ziv, and R. Catane, "Tumor lysis syndrome in nonhematologic malignancies: report of a case and review of the literature," American Journal of Clinical Oncology, vol. 17, no. 6, pp. 502-505, 1994.

[66] Y. Ustundag, S. Boyacioglu, I. C. Haznedaroglu, and E. Baltali, "Acute tumor lysis syndrome associated with paclitaxel," Annals of Pharmacotherapy, vol. 31, no. 12, pp. 1548-1549, 1997.

[67] A. Y. Rostom, G. El-Hussainy, A. Kandil, and A. Allam, "Tumor lysis syndrome following hemi-body irradiation for metastatic breast cancer," Annals of Oncology, vol. 11, no. 10, pp. 1349-1351, 2000.

[68] K. Mevlüt, E. Orhan, E. Huseyin, and G. Nilufer, "Tumor lysis syndrome following a single dose of capecitabine," The Annals of Pharmacotherapy, vol. 38, article 902, 2004.

[69] S. F. A. Bilgrami and B. G. Fallon, "Tumor lysis syndrome after combination chemotherapy for ovarian cancer," Medical and Pediatric Oncology, vol. 21, no. 7, pp. 521-524, 1993.

[70] J. K. Chan, S. S. Lin, D. S. McMeekin, and M. L. Berman, "Patients with malignancy requiring urgent therapy: case 3. Tumor lysis syndrome associated with chemotherapy in ovarian cancer," Journal of Clinical Oncology, vol. 23, no. 27, pp. 6794-6795, 2005.

[71] H. Godoy, J. P. Kesterson, and S. Lele, “Tumor lysis syndrome associated with carboplatin and paclitaxel in a woman with recurrent endometrial cancer," International Journal of Gynecology and Obstetrics, vol. 109, no. 3, p. 254, 2010.

[72] A. I. Shamseddine, A. M. Khalil, and M. H. Wehbeh, "Acute tumor lysis syndrome with squamous cell carcinoma of the vulva," Gynecologic Oncology, vol. 51, no. 2, pp. 258-260, 1993.

[73] A. Khalil, M. Chammas, A. Shamseddine, and M. Seoud, "Fatal acute tumor lysis syndrome following treatment of vulvar carcinoma: case report," European Journal of Gynaecological Oncology, vol. 19, no. 4, pp. 415-416, 1998.

[74] K. Yokoi, N. Miyazawa, Y. Kano et al., "Tumor lysis syndrome in invasive thymoma with peripheral blood T-cell lymphocytosis," American Journal of Clinical Oncology, vol. 20, no. 1, pp. 86-89, 1997.

[75] A. D. Trobaugh-Lotrario, X. Liang, J. S. Janik, M. A. Lovell, and L. F. Odom, "Difficult diagnostic and therapeutic cases: case 2. thymoma and tumor lysis syndrome in an adolescent," Journal of Clinical Oncology, vol. 22, no. 5, pp. 955-957, 2004.

[76] L. M. Minasian, T. P. Szatrowski, M. Rosenblum et al., "Hemorrhagic tumor necrosis during a pilot trial of tumor necrosis factor- $\alpha$ and anti-GD3 ganglioside monoclonal antibody in patients with metastatic melanoma," Blood, vol. 83, no. 1, pp. 56-64, 1994.

[77] M. P. Castro, J. VanAuken, P. Spencer-Cisek, S. Legha, and R. W. Sponzo, "Acute tumor lysis syndrome associated with concurrent biochemotherapy of metastatic melanoma: a case 
report and review of the literature," Cancer, vol. 85, pp. 10551059, 1999.

[78] J. Stoves, D. Richardson, and H. Patel, "Tumour lysis syndrome in a patient with metastatic melanoma treated with biochemotherapy," Nephrology Dialysis Transplantation, vol. 16, no. 1, pp. 188-189, 2001.

[79] G. S. Habib and W. R. Saliba, "Tumor lysis syndrome after hydrocortisone treatment in metastatic melanoma: a case report and review of the literature," American Journal of the Medical Sciences, vol. 323, no. 3, pp. 155-157, 2002.

[80] K. J. Busam, J. Wolchok, A. A. Jungbluth, and P. Chapman, "Diffuse melanosis after chemotherapy-induced tumor lysis syndrome in a patient with metastatic melanoma," Journal of Cutaneous Pathology, vol. 31, no. 3, pp. 274-280, 2004.

[81] Y. Nakamura, Y. Nakamura, E. Hori et al., "Tumor lysis syndrome after transcatheter arterial infusion of cisplatin and embolization therapy for liver metastases of melanoma," International Journal of Dermatology, vol. 48, no. 7, pp. 763767, 2009.

[82] E. Borne, R. Serafi, F. Piette, and L. Mortier, "Tumour lysis syndrome induced by corticosteroid in metastatic melanoma presenting with initial hyperkalemia," Journal of the European Academy of Dermatology and Venereology, vol. 23, no. 7, pp. 855-856, 2009.

[83] S. Schuman, J. M. Pearson, J. A. Lucci, and L. B. Twiggs, "Metastatic gestational trophoblastic neoplasia complicated by tumor lysis syndrome, heart failure, and thyrotoxicosis: a case report," Journal of Reproductive Medicine for the Obstetrician and Gynecologist, vol. 55, no. 10, pp. 441-444, 2010.

[84] C. D. Blanke, M. P. A. Hemmer, and R. S. Witte, "Acute tumor lysis syndrome with choriocarcinoma," Southern Medical Journal, vol. 93, no. 9, pp. 916-919, 2000.

[85] G. Feres, J. I. Salluh, C. Ferreira, and M. Soares, "Severe acute tumor lysis syndrome in patients with germ-cell tumors," Indian Journal of Urology, vol. 24, no. 4, pp. 555-557, 2008.

[86] R. D. W. Hain, L. Rayner, S. Weitzman, and A. Lorenzana, "Acute tumour lysis syndrome complicating treatment of stage IVS neuroblastoma in infants under six months old," Medical and Pediatric Oncology, vol. 23, no. 2, pp. 136-139, 1994.

[87] B. H. Kushner, M. P. LaQuaglia, S. Modak, and N. K. V. Cheung, "Tumor lysis syndrome, neuroblastoma, and correlation between serum lactate dehydrogenase levels and MYCN-amplification," Medical and Pediatric Oncology, vol. 41, no. 1, pp. 80-82, 2003.

[88] G. C. Tomlinson and L. A. Solberg, "Acute tumor lysis syndrome with metastatic medulloblastoma. A case report," Cancer, vol. 53, no. 8, pp. 1783-1785, 1984.

[89] L. Baeksgaard and J. B. Sorensen, "Acute tumor lusis syndrome in solid tumors - a case report and review of the literature," Cancer Chemotherapy and Pharmacology, vol. 51, pp. 187-192, 2003.

[90] J. E. Gold, S. C. Malamud, F. LaRosa, and M. E. Osband, "Adoptive chemoimmunotherapy using ex vivo activated memory T-cells and cyclophosphamide: tumor lysis syndrome of a metastatic soft tissue sarcoma," American Journal of Hematology, vol. 44, no. 1, pp. 42-47, 1993.

[91] J. Khan and V. A. Broadbent, "Tumor lysis syndrome complicating treatment of widespread metastatic abdominal rhabdomyosarcoma," Pediatric Hematology and Oncology, vol. 10, no. 2, pp. 151-155, 1993.

[92] K. Q. Qian, H. Ye, Y. W. Xiao, Y. Y. Bao, and C. J. Qi, "Tumor lysis syndrome associated with chemotherapy in primary retroperitoneal soft tissue sarcoma by ex vivo ATPbased tumor chemo-sensitivity assay (ATP-TCA)," International Journal of General Medicine, vol. 2, pp. 1-4, 2009.

[93] Y. Hiraizumi, S. Kamoy, Y. Inde, K. Kurose, Y. Ohaki, and T. Takeshita, "A case of tumor lysis syndrome following chemotherapy for a uterine epithelioid leiomyosarcoma with focal rhabdomyosarcomatous differentiation," The Journal of Obstetrics and Gynaecology Research, vol. 37, pp. 1-6, 2011.

[94] A. Will and E. Tholouli, "The clinical management of tumour lysis syndrome in haematological malignancies," British Journal of Haematology, vol. 154, no. 1, pp. 3-13, 2011.

[95] M. R. Zonfrillo, "Management of pediatric tumor lysis syndrome in the emergency department," Emergency Medicine Clinics of North America, vol. 27, no. 3, pp. 497-504, 2009.

[96] R. Seth and A. S. Bhat, "Management of common oncologic emergencies," Indian Journal of Pediatrics, vol. 78, no. 6, pp. 709-717, 2011. 


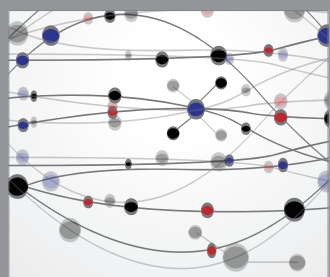

The Scientific World Journal
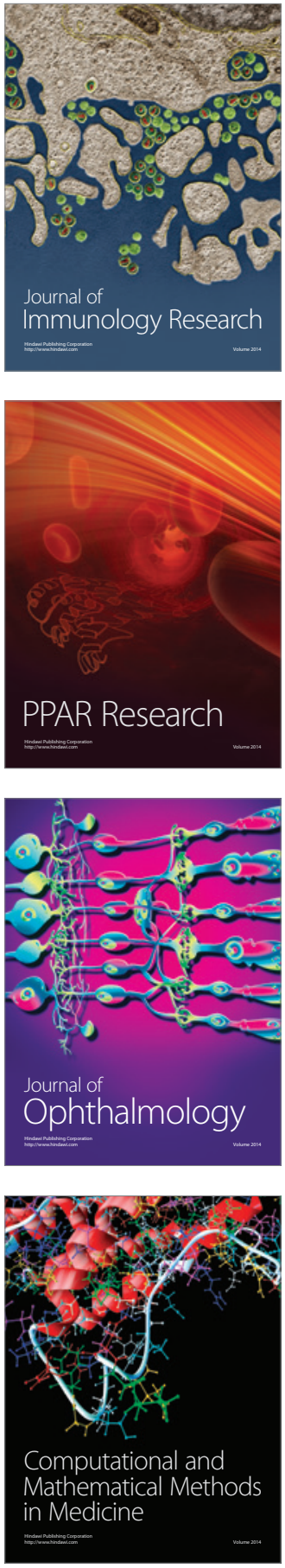

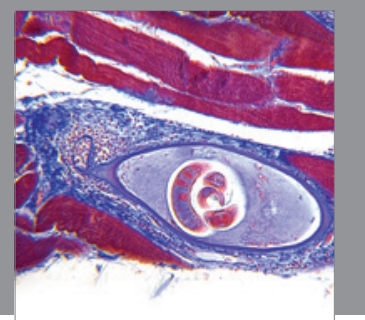

Gastroenterology

Research and Practice
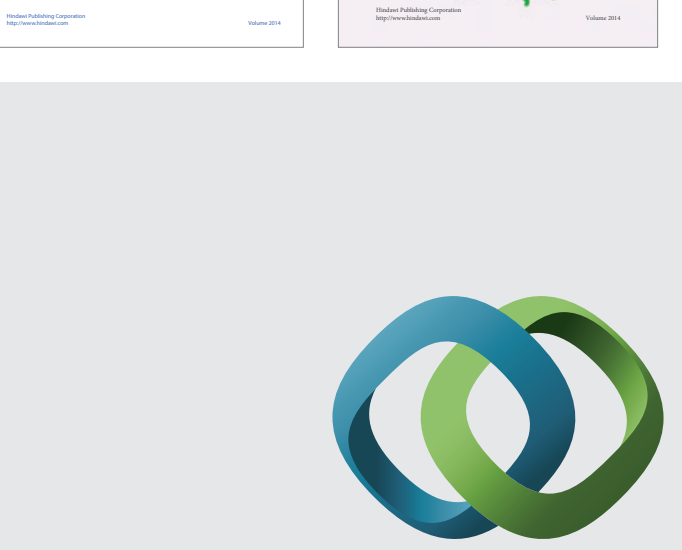

\section{Hindawi}

Submit your manuscripts at

http://www.hindawi.com
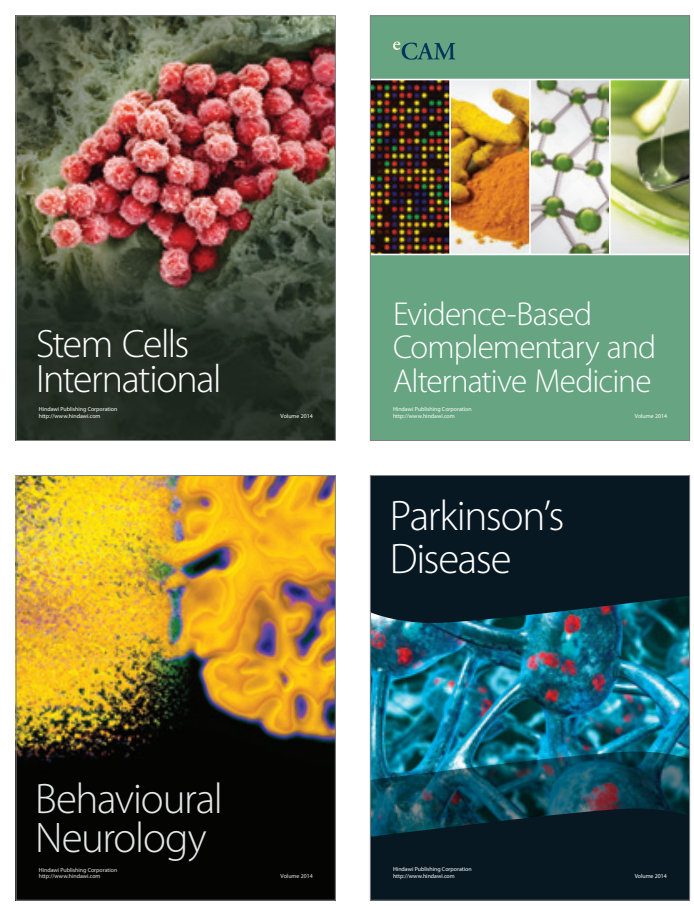

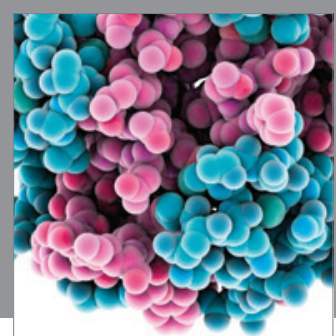

Journal of
Diabetes Research

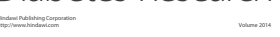

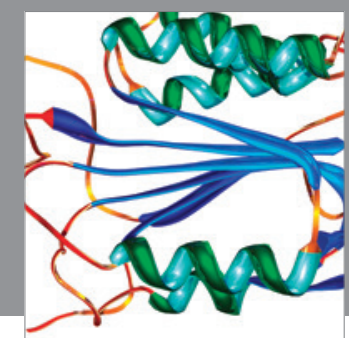

Disease Markers
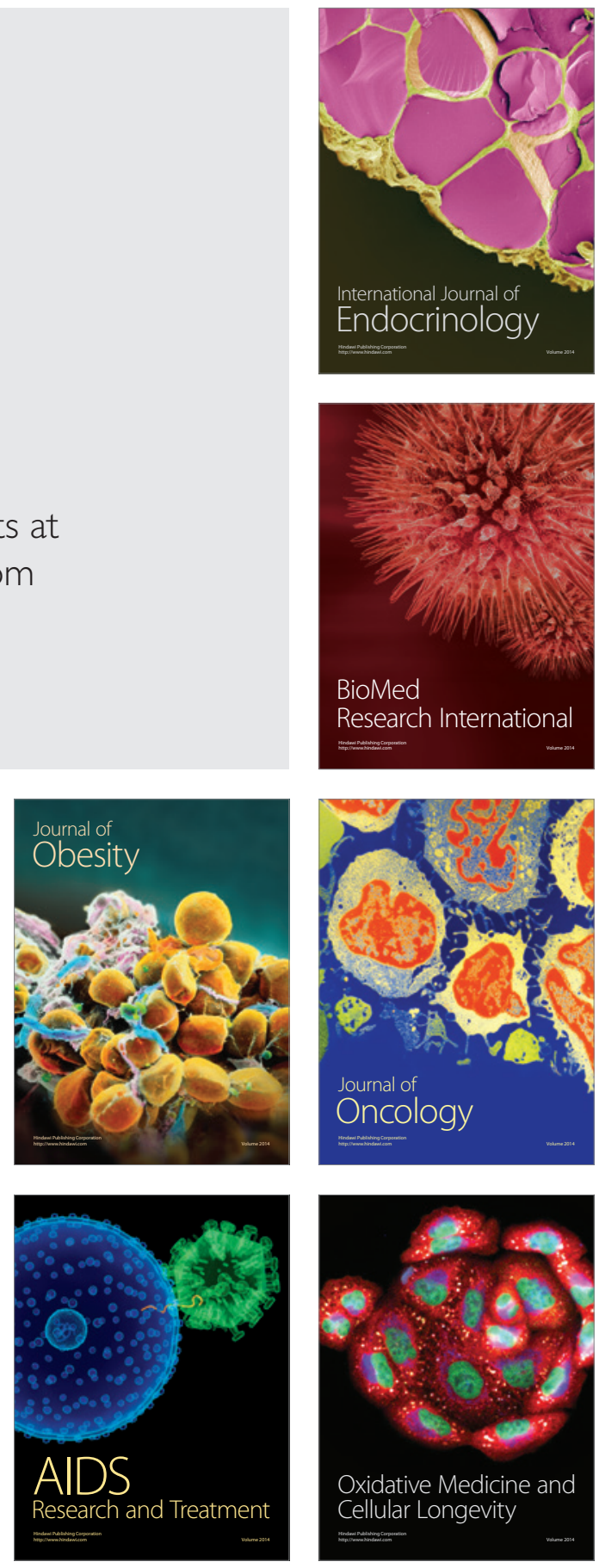